\title{
Iniciação e emergência de afilhos em cereais de estação fria
}

\author{
Initiation and emergence of tillers in small-grain cereals
}

\author{
Antonio Carlos Alves ${ }^{1}$ Claudio Mario Mundstock ${ }^{2}$ João de Deus Medeiros ${ }^{3}$
}

\section{RESUMO}

A iniciação e emergência de afilhos e, principalmente, aquele do coleóptilo foram estudadas para verificar o potencial de afilhamento dos cereais de estação fria. Para tanto, foram conduzidos ensaios em telado e câmara de crescimento com genótipos de trigo, IPF-49865 (mutante unicolmo), EMBRAPA-16 e BR-23 (multicolmo), de aveia, UFRGS-10 e de cevada, FM-519. Nestes, avaliaram-se o desenvolvimento foliar do colmo principal e dos afilhos primários e a iniciação dos afilhos. A iniciação de todos os primórdios de afilhos, inclusive o do coleóptilo, ocorreu de maneira seqüencial nas primeiras folhas das plantas mas o mesmo comportamento não foi observado na emergência dos afilhos. $O$ afilho do coleóptilo mostrou um comportamento anormal. No entanto, para ocorrer um desenvolvimento sincronizado do colmo principal com os afilhos da planta deverão buscar-se genótipos de cereais de estação fria que expressem esse afilho.

Palavras-chave: anatomia, morfologia, gramíneas, primórdio.

\section{ABSTRACT}

The initiation and emergence of the tiller and mainly of the coleoptile tiller were studied to verify the tillering potential of small-grain cereals. The studies were carried out on open air and growth chamber using the wheat genotypes IPF-49865 (mutant uniculm), EMBRAPA-16 and BR-23 (multiculm), the oat genotypes UFRGS-10, and the barley genotype FM-519. The evaluations included the leaf development of the main culm and of the primary tillers, and the initiation of the tillers. The initiation of all tillers primordium, including the coleoptile, occurred sequentially in the first leaves of the plants but the same pattern was not observed for the emergence of the tillers. The coleoptile tiller showed an abnormal behavior. However, in order to occur a synchronized development of the main culm and the tillers it is suggested that genotypes of small-grain cereals which express this tiller should be searched for.

Key words: anatomy, morphology, graminae, primordium.

\section{INTRODUÇÃO}

O afilhamento dos cereais de estação fria pode ser uma característica importante e desejável sob as condições climáticas do Sul do Brasil. A variação ambiental na qual esses cereais são cultivados exige cultivares com grande plasticidade de modo a responder a essas variações.

O estudo do potencial de afilhamento em gramíneas geralmente não determina a iniciação dos primórdios de afilhos mas registra apenas sua emergência a partir das axilas das folhas. Esta dificuldade em se observar a iniciação dos primórdios de afilhos em gramíneas, quando se avalia o potencial de afilhamento, pode gerar conclusões errôneas pois, na maioria das vezes, não é possível afirmar se o afilho não iniciou ou apenas não emergiu.

\footnotetext{
${ }^{1}$ Engenheiro Agrônomo, Doutor, Professor Adjunto, Departamento de Fitotecnia, Centro de Ciências Agrárias, Universidade Federal de Santa Catarina (UFSC), CP 476, 88040-900, Florianópolis, SC. E-mail: alves@cca.ufsc.br. Autor para correspondência.

${ }^{2}$ Engenheiro Agrônomo, PhD, Professor Titular, Bolsista do Conselho Nacional de Desenvolvimento Científico e Tecnológico (CNPq), Departamento de Plantas de Lavoura, Faculdade de Agronomia, Universidade Federal do Rio Grande do Sul, CP 776, 91501-970, Porto Alegre, RS. E-mail: cmmundst@vortex.ufrgs.br

${ }^{3}$ Biológo, Doutor, Professor Adjunto, Departamento de Botânica, Centro de Ciências Biológicas, UFSC. E-mail: jdmedeiros@ccb.ufsc.br
} 
As gemas axilares, ainda na forma de primórdios de afilhos, são encontradas na maioria das axilas das folhas de gramíneas. Antes da germinação, o embrião maduro da semente de trigo possui um primórdio de afilho no nó do coleóptilo. Esse primórdio pode desenvolver ou permanecer dormente (inibido) (PETERSON et al., 1982). McCALL (1934) encontrou na axila de cada folha de trigo um primórdio de afilho, similar ao encontrado na axila do coleóptilo. MARSHALL \& BOYD (1985) encontraram em um genótipo de trigo classificado como de baixo afilhamento (bicolmo), em média, 6,9 afilhos por planta. Dessa forma, parece que genótipos com baixo potencial de afilhamento, inclusive os unicolmos, não diferem dos multicolmo no que se refere à iniciação de primórdios de gemas laterais.

A emergência de afilhos a campo geralmente é baixa e principalmente a emergência do afilho do coleóptilo (ALMEIDA et al., 2000, ALVES et al., 2000 e ALVES et al., 2004). No entanto, o afilho do coleóptilo é um afilho importante porque, em muitos casos, a diferença no afilhamento das gramíneas está justamente no desenvolvimento desse afilho (SKINNER \& NELSON, 1994), embora seu desenvolvimento seja anômalo em relação aos demais (McMASTER, 1997). SKINNER \& NELSON (1994) observaram que populações de plantas de festuca (Festuca arundinacea Schreb.) com baixa velocidade no alongamento foliar produziram duas vezes mais afilhos do coleóptilo do que aquelas com alta velocidade no alongamento foliar. Esses afilhos e seus subafilhos contribuíram com $80 \%$ da diferença no número de afilhos por planta. Com exceção do afilho do coleóptilo, não houve diferença no afilhamento entre populações. LIANG \& RICHARDS (1994) observaram que plantas de trigo com afilho do coleóptilo bem desenvolvido (grande) apresentaram acréscimo de 24 a 30\% na área foliar e peso seco em relação àquelas com mau desenvolvimento (pequeno) e/ou ausência desse afilho. As plantas com essa característica não inibiram o desenvolvimento dos demais afilhos. Com base nessas informações, os autores sugerem que plantas de trigo com alto vigor inicial devem ser selecionadas com as características de folhas grandes no ínicio do desenvolvimento da planta e presença do afilho do coleóptilo.

Levando em consideração a importância dos afilhos para a produção de grãos, o objetivo deste trabalho foi verificar o potencial de iniciação de afilhos em cereais de estação fria e, principalmente do afilho do coleóptilo.

\section{MATERIAL E MÉTODOS}

O presente estudo foi realizado através da implantação de um ensaio em telado utilizando-se dois genótipos de trigo (Triticum aestivum L.): EMBRAPA16 e IPF-49865. Também foram cultivadas plantas de trigo: BR-23, EMBRAPA-16 e IPF-49865, aveia (Avena sativa L.): UFRGS-10 e cevada (Hordeum vulgare L.): FM-519 em câmaras de crescimento e sob telado para observação da iniciação de afilhos.

O desenvolvimento das folhas do colmo principal e dos afilhos foram avaliados através da escala proposta por HAUN (1973). Essa escala baseia-se na notação decimal do crescimento das folhas, sendo a notação 0,5 correspondente a um colmo com a primeira folha expandida em $50 \%$ do seu tamanho final. Nessa mesma escala, 1,0 corresponde à primeira folha totalmente (100\%) expandida.

O experimento foi implantado sob telado no Departamento de Botânica do Centro de Ciências Biológicas da Universidade Federal de Santa Catarina, em Florianópolis. O solo utilizado como substrato apresentou as seguintes características físico-químicas: argila: 21\%; $\mathrm{pH}$ : 6,9; valor $\mathrm{pH}-\mathrm{SMP}$ (Shoemaker, Maclean e Pratt): 6,9; P: + 50 $\mathrm{mg} \mathrm{dm}^{-3}$; K: +150mg dm${ }^{-3}$; M.O.: 59g kj ${ }^{-1}$; Al: 0,0 $\mathrm{Cmol}_{\mathrm{c}} \mathrm{dm}^{-3}$; Ca: 4,8Cmol $\mathrm{dm}^{-3}$; $\mathrm{Mg}: 2,6 \mathrm{Cmol}_{\mathrm{C}} \mathrm{dm}^{-3}$. Foi aplicado semanalmente nitrogênio em cobertura, na base de $10 \mathrm{~kg}$ ha $^{-1}$ de uréia durante o decorrer do experimento. A duração do experimento foi de 43 dias desde a emergência até a última observação. Os vasos (parcelas) utilizados possuíam $35 \mathrm{~cm}$ de altura e $18 \mathrm{~cm}$ de diâmetro e foram preenchidos com solo até $30 \mathrm{~cm}$ de altura. Foram utilizados dois genótipos de trigo: IPF 49865, classificado como unicolmo, que foi cedido pelo Centro Nacional de Pesquisa do Trigo da EMBRAPA, localizado em Passo Fundo (RS) e a cultivar EMBRAPA-16 (cultivar comercial de trigo recomendada para o sul do Brasil), classificada como multicolmo, com características de alto afilhamento. Os tratamentos foram as combinações entre duas densidades de plantas (1 e 12 plantas por vaso) e os dois genótipos de trigo citados, com quatro repetições por tratamento. O delineamento experimental foi o inteiramente casualizado e os dados foram submetidos à análise de variância e as diferenças entre médias analisadas pelo teste de Duncan, a 5\%. Foram observados aos 43 dias após a emergência: o desenvolvimento foliar do colmo principal e dos afilhos primários, número de afilhos primários, percentagem de emergência dos afilhos primários e número total de afilhos primários e secundários. Após o término do ensaio, as plantas foram coletadas e 
fixadas em glutaraldeído (glutaraldeído 25\% e tampão fosfato $0,1 \mathrm{M}$ para $\mathrm{pH} 7,2$ ) e armazenadas em álcool etílico 70GL para análise histológica segundo KOEHLER (1973).

Cultivo de plantas para análises histológicas - Plantas de aveia (UFRGS-10), cevada (FM-519) e trigo (BR-23) foram cultivadas em câmaras de crescimento modelo Percival com radiação incidente de 0,221 calm ${ }^{-2} \mathrm{~min}$. (ao nível das plantas), fotoperíodo de 11/13 horas - diurno/noturno, temperatura de $20 / 10^{\circ} \mathrm{C}$ - diurna/noturna e umidade relativa do ar aproximada de $70 \%$. O solo utilizado apresentou as seguintes características químicas: $\mathrm{pH}$ : 5,5; P: $12 \mathrm{mg} \mathrm{dm}^{-3}$; K: $108 \mathrm{mg} \mathrm{dm}^{-3}$; alumínio: $0,0 \mathrm{Cmol} \mathrm{dm}^{-3}$ e matéria orgânica: 1,6 \%. A adubação foi realizada com $28,1 \mathrm{mg}$ de nitrogênio $\left[\left(\mathrm{NH}_{4}\right)_{2} \mathrm{SO}_{4} \mathrm{e}\right.$ $\left.\left(\mathrm{NH}_{4}\right)_{2} \mathrm{HPO}_{4}\right], 21,8 \mathrm{mg}$ de fósforo [ $\left.\left(\mathrm{NH}_{4}\right)_{2} \mathrm{HPO}_{4}\right]$ e $16,7 \mathrm{mg}$ de potássio $(\mathrm{KCl})$, para cada quilograma de solo seco. As adubações de cobertura com nitrogênio (25 mg kg-1 de solo seco), foram realizadas semanalmente, utilizando-se $\left(\mathrm{NH}_{4}\right)_{2} \mathrm{HPO}_{4}$. Foram coletadas plantas até aos 42 dias após a emergência das plântulas com ausência na emissão de filhos. A característica morfológica analisada foi o desenvolvimento das folhas do colmo principal (HAUN, 1973).

Análises histológicas foram realizadas em plantas de trigo, aveia e cevada, cultivadas em câmara de crescimento para verificar a iniciação dos primórdios de afilhos que não haviam emergido. As amostras de trigo foram fixadas em glutaraldeído e armazenadas em álcool etílico 70GL enquanto as demais amostras foram fixadas em FAA 50GL (JOHANSEN, 1940) e armazenadas em álcool etílico 70GL.

Após a fixação, as amostras foram desidratadas em séries alcoólica etílica e infiltradas com parafina, segundo técnicas usuais descritas por JOHANSEN (1940) e SASS (1966), emblocadas e seccionadas transversal e longitudinalmente de forma seriada através de micrótomo rotativo modelo E. Zimmermann Leipzig. A espessura dos cortes variou de 8 a 18mm. Os cortes foram montados em lâminas permanentes e coloridos com safranina 50GL e Astra Blau (JOHANSEN, 1940). As ilustrações foram realizadas com o auxílio de câmara clara modelo Carl Zeiss - Jena A8.

\section{RESULTADOS E DISCUSSÃO}

As análises histológicas realizadas em genótipos de trigo (Figuras 1, 2, 3 e 4), cevada (Figura 5) e aveia (Figura 6) mostraram a iniciação dos primeiros primórdios de afilhos primários. Em amostras de trigo (cultivar BR-23) com um dia após a emergência (DAE) e aveia (cultivar UFRGS-10) e cevada (cultivar FM-519) cultivadas em câmara de crescimento, com desenvolvimento de 1,9 e 2,5 na escala Haun, foi observada a iniciação dos afilhos $\mathrm{A}_{0}$ e $\mathrm{A}_{1}$ (Figura 1 ), $\mathrm{A}_{0}$, $A_{1}$ e $A_{2}$ (Figuras 6) e $A_{0}, A_{1}, A_{2}$ e $A_{3}$ (Figura 5), respectivamente. Em todas as amostras analisadas, tanto nos genótipos unicolmo como multicolmo de trigo (Figuras 1, 2, 3 e 4) e em aveia (Figura 6) e cevada (Figura 5) foi observada a iniciação do $\mathrm{A}_{0}$.

No primeiro dia após a emergência do trigo, os afilhos $\mathrm{A}_{0}$ e $\mathrm{A}_{1}$ haviam iniciados e, aos $26 \mathrm{DAE}$, encontravam-se iniciados os afilhos $\mathrm{A}_{0}$ até $\mathrm{A}_{5}$. Devese ressaltar que não houve falha na iniciação dos primórdios de afilhos nos primeiros nós do colmo principal nas espécies analisadas. Nas situações em que não ocorreu a emergência dos afilhos, as análises histológicas mostraram que, mesmo assim, eles haviam iniciado (Figuras 4 e 5). Os genótipos unicolmo e multicolmo não diferiram quanto ao potencial de iniciação de afilhos, tal como haviam observado BOKHARI \& YOUNGER (1971) e MARSHALL \& BOYD(1985).

Portanto, a iniciação de afilhos primários ocorreu de uma maneira sucessiva do nó do coleóptilo até os primeiros nós do colmo principal das plantas analisadas. Isso confirmou as observações sobre o potencial de afilhamento em gramíneas realizadas por McCALL (1934), BOKHARI \& YOUNGER (1971) e MCMASTER (1997).

Dessa maneira, o controle do desenvolvimento dos afilhos não ocorreu na diferenciação ou iniciação dos mesmos mas, durante e após a sua emergência. SKINNER \& NELSON (1995) sugeriram que a dominância apical é menos importante em regular o desenvolvimento de afilhos comparado ao papel da ramificação em dicotiledôneas. Esses autores observaram que a coordenação entre o desenvolvimento de folhas e iniciação de primórdios de afilhos é mais importante em gramíneas do que a dominância apical em dicotiledôneas.

No entanto, os primórdios primários iniciados nos primeiros nós de plantas de trigo desenvolveram- se parcialmente. Ocorreu falha principalmente na emergência do $\mathrm{A}_{0}$ e dos afilhos dos nós superiores da planta (os últimos a emergir). A emergência do $\mathrm{A}_{0}$ não mostrou diferença significativa (Tabela 1). O comportamento anômalo do $\mathrm{A}_{0}$ (McCALL, 1934, FLETCHER \& DALE, 1974, McMASTER, 1997, ALVES et al., 2000 e ALVES et al., 2004) ficou bem caracterizado e não foi possível comparar a sua emergência entre genótipos e entre densidade de plantas devido ao seu alto coeficien- 


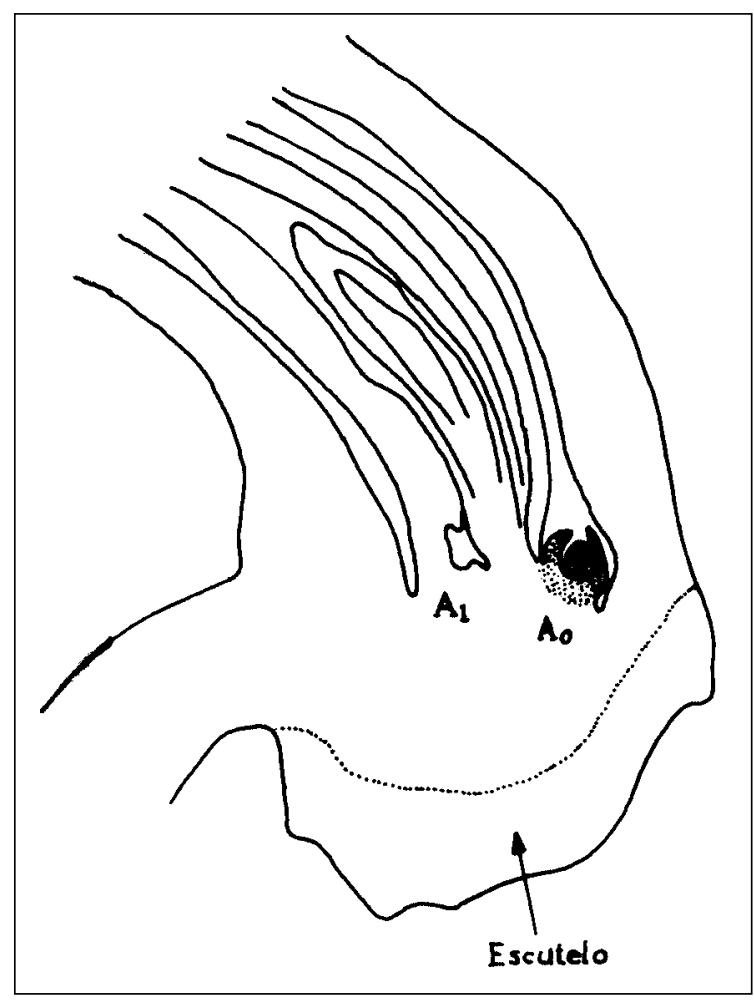

Figura 1 - Plântula de Triticum aestivum, cv BR-23, com um dia após a emergência, em secção longitudinal, mostrando o afilho do coleóptilo ( $\left.\mathrm{A}_{0}\right)$ e o $\mathrm{A}_{1}(25,6 \mathrm{x})$.

te de variação (Tabela 1). FLETCHER \& DALE (1974) atribuíram a baixa freqüência de emergência do $A_{0}$ ao seu posicionamento, uma vez que esse estaria numa posição anatômica de difícil vascularização. Para trigo e cevada, McCALL (1934) e FLETCHER \& DALE (1974) respectivamente, também sugeriram que falhas na conexão vascular entre esse afilho e o resto da planta seria o motivo do seu não desenvolvimento. No entanto, a origem axilar do $\mathrm{A}_{0}$, assim como dos demais afilhos, como ficou demonstrado neste trabalho, não corroboram com as explicações dadas por esses autores. Pelo contrário, a origem axilar desse afilho facilitou o seu desenvolvimento. Ele diferencia-se diretamente do meristema apical, não envolvendo prévia desdiferenciação de tecido (KERSTETTER \& HAKE, 1997). A origem e posição do $\mathrm{A}_{0}$ também facilita sua conexão vascular com o resto da planta (ESAU, 1965 e ALVES et al., 2000). Portanto, o não desenvolvimento do $A_{0}$ deve apresentar outras razões que não sua iniciação, origem e posição anatômica dentro da planta.

A evolução da emergência dos demais afilhos acompanhou o desenvolvimento das plantas. A comparação, com base na emergência, entre os genótipos unicolmo e multicolmo de trigo sob baixa densidade de

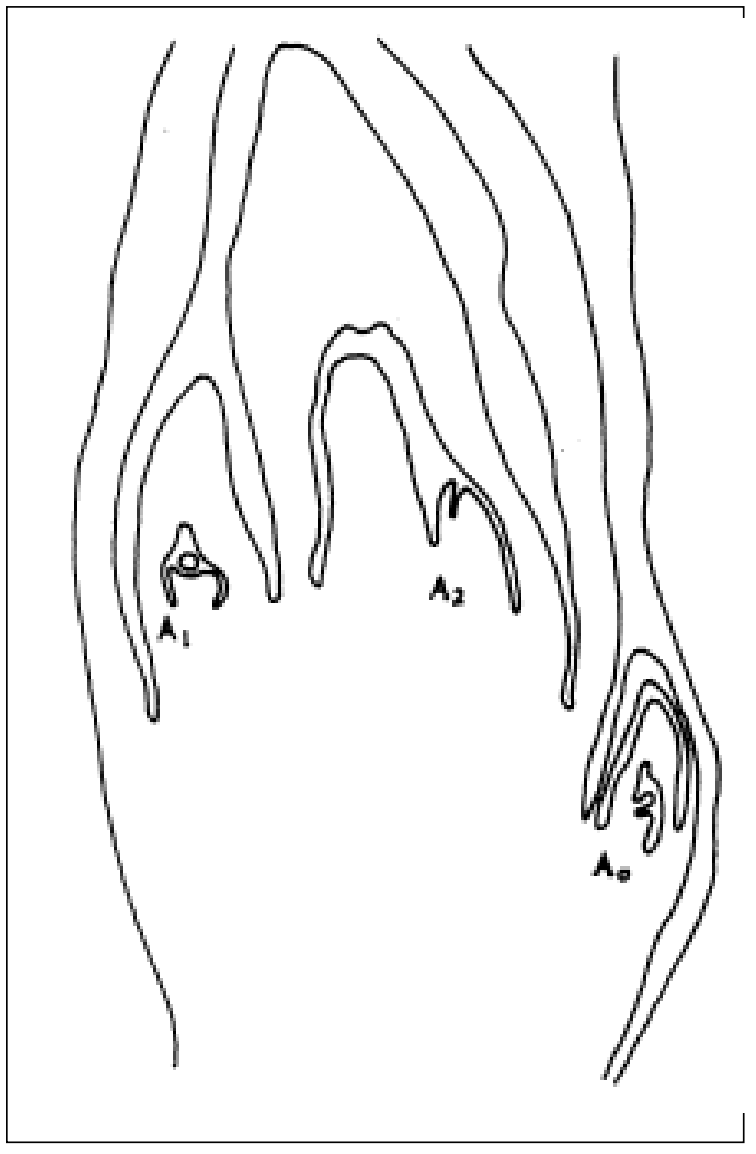

Figura 2 - Plântula de Triticum aestivum, linhagem unicolmo IPF-49865, com 12 dias após a emergência, em secção longitudinal, mostrando os afilhos $A_{0}, A_{1} e$ $A_{2}(40 x)$.

plantas mostrou que aos 43 DAE a emergência dos afilhos $A_{1}$ ao $A_{5}$ foi de $100 \%$ para os genótipos unicolmo e multicolmo e a emergência do $A_{6}$ foi de $0 \%$ no unicolmo e de $50 \%$ no multicolmo (Tabela 1). A análise da emergência dos afilhos mostrou que os últimos afilhos do genótipo unicolmo apresentaram uma menor percentagem de emergência em relação ao genótipo multicolmo (Tabela 1). Isso sugere que a velocidade de emergência dos afilhos do genótipo unicolmo foi mais lenta que do genótipo multicolmo. Por isso, numa situação de competição a campo, esses afilhos não sobrevivem como é geralmente observado (MARSHALL \& BOYD, $1985 \mathrm{e}$ DOFING, 1996).

Diferenças entre genótipos unicolmo e multicolmo, quanto ao afilhamento, não foram apenas de ordem genética e sim pela interação entre genótipo e ambiente como foi mostrado (Tabela 1). As diferenças, no entanto, aparecem quando os genótipos são cultivados a campo e com alta densidade de plantas (DOFING, 1996). Isso sugere que, em condições de campo e sob alta densidade de plantas, ocorre uma relação hormonal desequili- 


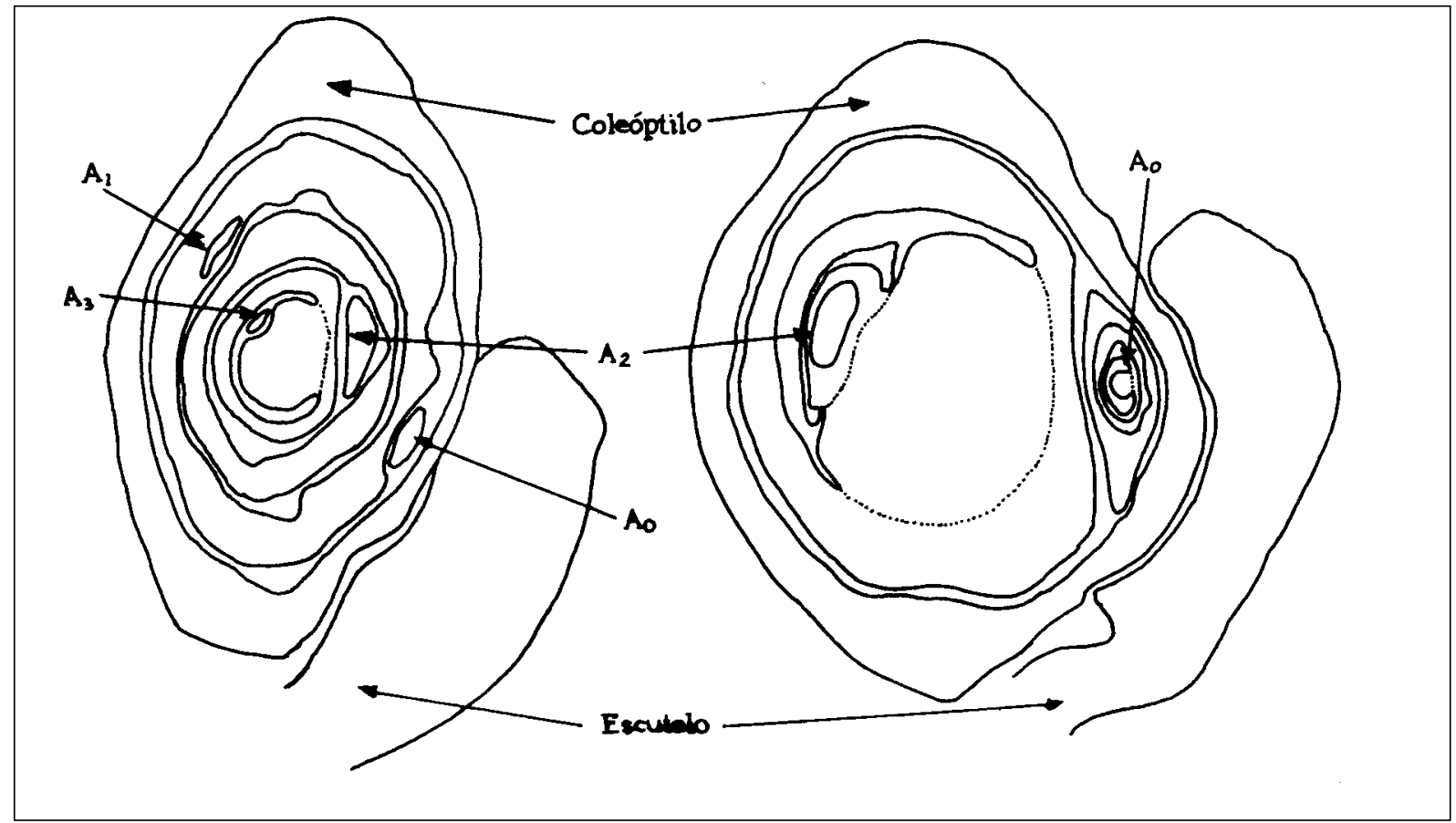

Figura 3 - Plântula de Triticum aestivum, linhagem unicolmo IPF-49865, com nove dias após a emergência, em secção transversal. a. Corte próximo a base do colmo principal mostrando os afilhos $A_{0}, A_{1}, A_{2}$ e $A_{3}$. b. Corte próximo ao ápice do colmo principal mostrando os afilhos $A_{0}$ e $A_{2}(40 x)$.

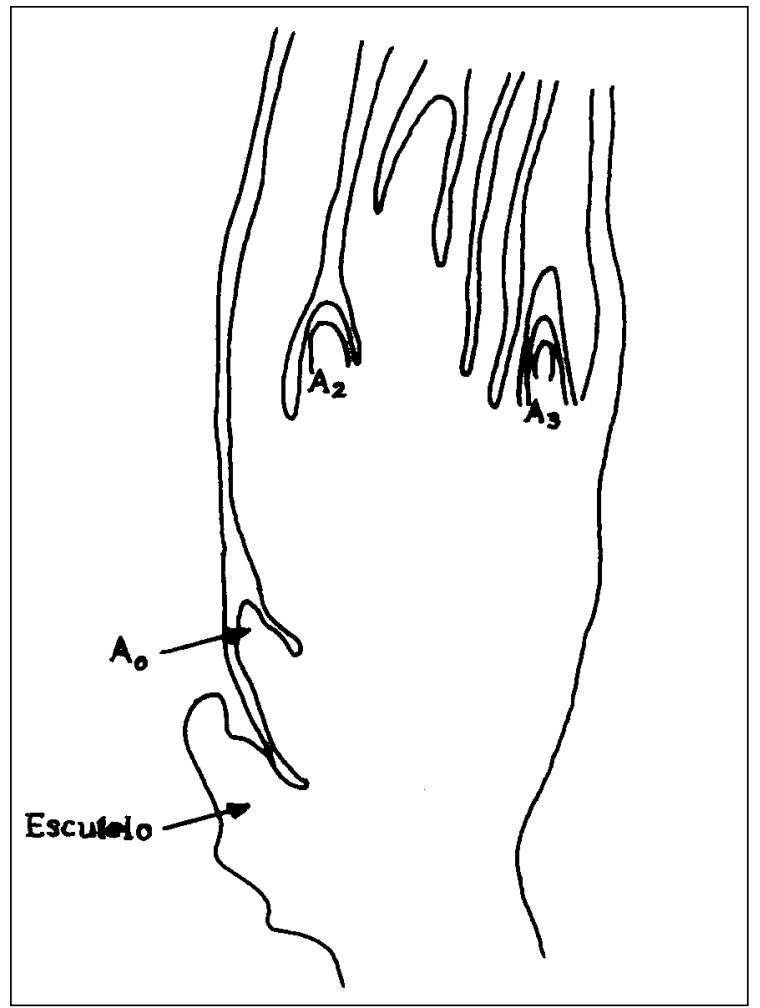

Figura 4 - Plântula de Triticum aestivum, cv EMBRAPA-16, com 12 dias após a emergência, em secção longitudinal, mostrando os afilhos $A_{0}, A_{2}$ e $A_{3}(25,6 x)$.

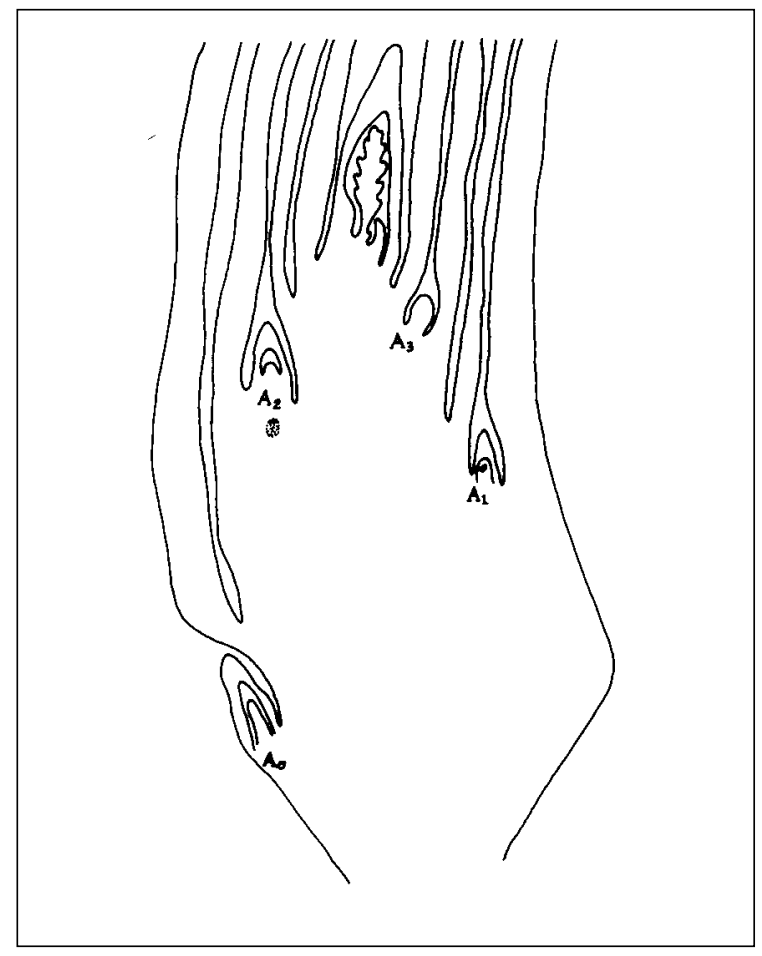

Figura 5 - Plântula de Hordeum vulgare, cv. FM-519, com desenvolvimento foliar de 2,5 (escala Haun), em secção longitudinal, mostrando os afilhos $A_{0}, A_{1}, A_{2}$ e $A_{3}$ iniciados e posteriormente inibidos (40x).

Ciência Rural, v.35, n.1, jan-fev, 2005. 


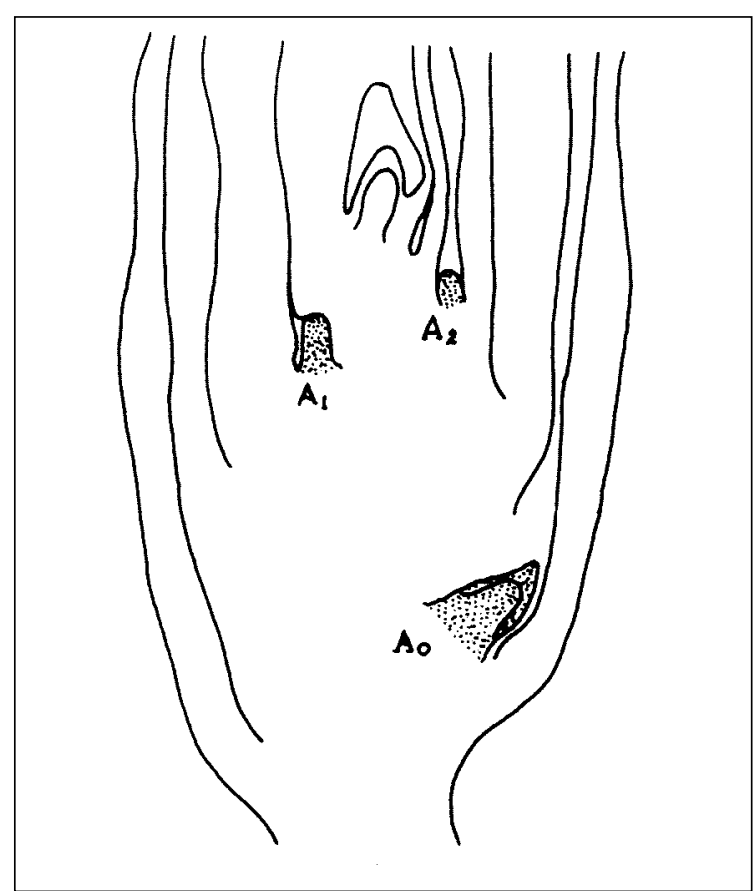

Figura 6 - Plântula de Avena sativa, cv UFRGS-10, com desenvolvimento foliar de 1,9 (escala Haun), em secção longitudinal, mostrando os afilhos $\mathrm{A}_{0}, \mathrm{~A}_{1}$ e $\mathrm{A}_{2}$ $(25,6 x)$.

brada (TAMAS, 1995), causando uma maior redução no número de afilhos por planta. Desse modo, a sincronização entre a divisão e o alongamento celular (KAUFMAN et al., 1965 e SKINNER \& NELSON, 1995) e entre o desenvolvimento do afilho e do resto da planta pode ter sido afetada.

Tabela 1 - Número de folhas (escala Haun) do colmo principal (CP) e dos afilhos primários e emergência (\%) de afilhos primários de genótipos de trigo unicolmo (IPF-49865) e multicolmo (EMBRAPA-16) em função de duas densidades de plantas. Amostragem realizada aos 43 dias após a emergência das plântulas.

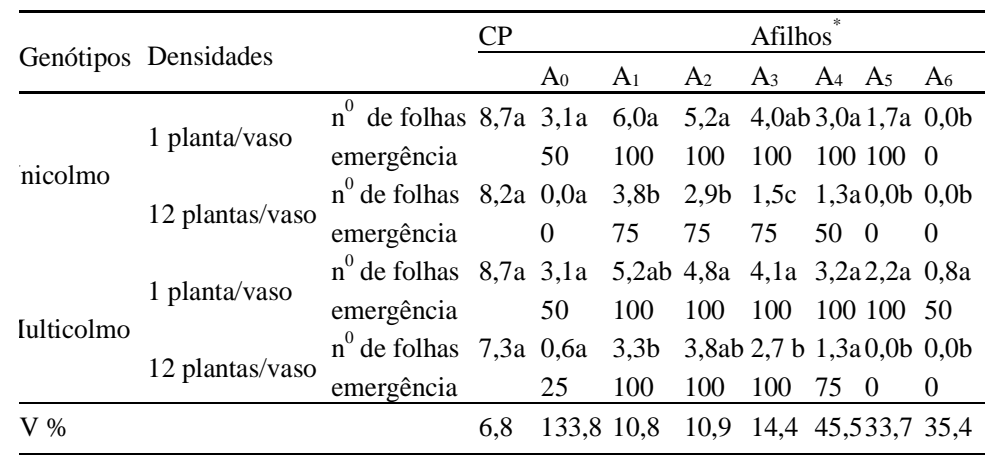

Médias seguidas da mesma letra na coluna não diferem significativamente pelo teste de Duncan $5 \%$.

* $A_{0}, A_{1}, A_{2}, A_{3}, A_{4}, A_{5}$ e $A_{6}$ correspondem aos afilhos no nó do coleóptilo, primeiro, segundo, terceiro, quarto, quinto e sexto nó do colmo principal, respectivamente.

\section{CONCLUSÃO}

A iniciação de todos os primórdios de afilhos ocorreu de uma maneira ordenada nas primeiras folhas dos cereais de inverno estudados. Portanto, o controle do desenvolvimento dos afilhos não ocorreu na diferenciação ou iniciação dos mesmos mas, durante e após a sua emergência. O afilho do coleóptilo foi o que apresentou comportamento anômalo em relação aos demais. No entanto, para se alcançar um crescimento sincronizado entre o CP e os afilhos, com vistas a obter maior rendimento e qualidade de grãos, sugere-se desenvolver genótipos nos quais ocorra o desenvolvimento desse afilho.

\section{REFERÊNCIAS BIBLIOGRÁFICAS}

ALMEIDA, M.L. et al. Evocação de afilhos pela qualidade da luz em plantas de trigo cultivadas em diferentes substratos. n.1, p.25-36, 2000.

ALVES, A.C. et al. Sistema vascular e controle do desenvolvimento de afilhos em cereais de estação fria. Revista Brasilei-

ALVES, A.C. et al. Emissão do afilho do coleóptilo em genótipos de aveia e em diferentes condições de estresse e manejo. Ciência Rural, Santa Maria, v.34, n.2, p.385-391, 2004

BOKHARI, U.G.; YOUNGER, V.V. Effects of CCC on tillering and flowering of uniculm barley. Crop Science, Madison, v.11, n.5, p.711-713, 1971.

DOFING, S.M. Near-isogenic analysis of uniculm and coventional-tillering barley lines. Crop Science, Madison, v.36, n.6, p.15231526, 1996.

ESAU, K. Vascular differentiation in plants. Santa Barbara: Holt : Rinehart and Winston, 1965. 160p.

FLETCHER, G.M.; DALE, J.E. Growth of tiller buds in barley: effects of shade treatment and mineral nutrition. Annals of Botany, London, v.38, p.63-76, 1974.

HAUN, J.R. Visual quantification of wheat development. Agronomy Journal, Madison, v.65, n.1, p.116-119, 1973

JOHANSEN, D.A. Plant microtechnique. New York : McGraw Hill, 1940. 523p.

KAUFAMN, P.B. et al. On nature of intercalary growth and cellular differentiation in internodes of Avena sativa. Botanical Gazette, Chicago, v.126, n.1,p.1-13, 1965.

Ciência Rural, v.35, n.1, jan-fev, 2005. 
KERSTETTER, R.A.; HAKE, S. Shoot meristem formation in vegetative development. The Plant Cell, Rockville, v.9, n.7, p.1001-1010, 1997.

KOEHLER, J.K. Advanced techniques in biological eletron microscopy. Berlin : Springer-Verlag,1973. $253 p$.

LIANG, Y.L; RICHARDS, R.A. Coleoptile tiller development is associated with fast early vigor in wheat. Euphytica, Wageningen, v.80, n.1/2, p.119-123, 1994.

MARSHALL, C.; BOYD, W.J.R. A comparison of the growth and development of biculm wheat lines with freely tillering cultivars. Journal Agricultural Science, Cambridge, v.104, n.1, p.163-171, 1985.

McCALL, M.A. Developmental anatomy and homologies in wheat. Journal of Agricultural Research, Washington, v.48, n.4, p.283-321, 1934.

McMASTER, R.A. Phenology, development, and growth the wheat (Triticum aestivum) shoot apex: A review. Advances in Agronomy, New York, v.59, p.63-118, 1997.

PETERSON, C.M. et al. Tiller development at the coleoptilar node in winter wheat. Agronomy Journal, Madison, v.74, n.5, p.781-784, 1982

SASS, J.E. Botanical mircotechnique. 3.ed. Ames : Iowa State University, 1966. 228p.

SKINNER, R.H.; NELSON, C.J. Role of leaf appearance rate and the coleoptile tiller in regulating tiller production. Crop Science, Madisnon, v.34, n.1, p.71-75, 1994.

SKINNER, R.H.; NELSON, C.J. Elongation of the grass leaf and its relationship to the phyllochron. Crop Science, Madison, v.35, n.1, p.4-10, 1995.

TAMAS, I.A. Hormonal regulation of apical dominance. In: DAVIES, P.J. (Ed.). Plant hormones: physiology, biochemistry and molecular biology. Dordrecht : Kuwer, 1995. 833p. p.572-597. 